\title{
A feasibility analysis of the ArcBlate MR-guided high-intensity focused ultrasound system for the ablation of uterine fibroids
}

\author{
Chin-Jung Wang ${ }^{1,2} \cdot$ Gigin Lin $^{2,3} \cdot$ Yi-Ting Huang ${ }^{1} \cdot$ Cindy Hsuan Weng ${ }^{1} \cdot$ Kai-Yun Wu ${ }^{1,2} \cdot$ Yu-Ying Su ${ }^{1}$ Yu-Shan Lin ${ }^{1}$. \\ Kit-Sum Mak ${ }^{1}$
}

Received: 18 May 2021 / Revised: 28 June 2021 / Accepted: 30 June 2021 / Published online: 9 July 2021

(c) The Author(s) 2021

\begin{abstract}
Purpose Uterine fibroids are benign gynecologic tumors and commonly occur in women by the age of 50. Women with symptomatic uterine fibroids generally receive surgical intervention, while they do not favor the invasive therapies. To evaluate the feasibility and safety of a novel magnetic resonance-guided high-intensity focused ultrasound (MRgHIFU) modality, ArcBlate, in the treatment of uterine fibroids.

Methods Nine patients with uterine fibroids and one patient with adenomyosis were treated with ArcBlate MRgHIFU. Tumor size and quality of life were evaluated postoperatively at 1 and 3 months by magnetic resonance imaging (MRI) and the 36-Item Short Form Survey (SF-36), respectively.

Results All patients completed the ArcBlate MRgHIFU procedure and there were no treatment-related adverse effects either during the procedure or during the 3 months of follow-up. Despite limiting the ablation volume to under $50 \%$ of the treated fibroid volume as a safety precaution, tumor volumes were markedly reduced in four patients by $15.78-58.87 \%$ at 3 -month post-treatment. Moreover, SF-36 scale scores had improved at 3 months from baseline by 2-8 points in six patients, indicating relief of symptoms and improved quality of life.

Conclusion This study evidence demonstrates the safety and feasibility of ArcBlate MRgHIFU and suggests its potential for treating uterine fibroids.
\end{abstract}

Keywords Uterine fibroid · Leiomyoma · Magnetic resonance-guided high-intensity focused ultrasound

\section{Introduction}

Uterine fibroids are benign gynecologic tumors found in the uterus $[1,2]$ and are the most common of all solid pelvic tumors, affecting $70 \%$ of women by age 50 years [3]. Many women with uterine fibroids are asymptomatic and

Chin-Jung Wang and Gigin Lin have contributed equally to this work.

Chin-Jung Wang

wang2260@gmail.com

1 Division of Gynecologic Endoscopy, Department of Obstetrics and Gynecology, Chang Gung Memorial Hospital at Linkou, Taoyuan, Taiwan

2 Chang Gung University College of Medicine, Taoyuan, Taiwan

3 Department of Medical Imaging and Intervention, Chang Gung Memorial Hospital at Linkou, Taoyuan, Taiwan underdiagnosed $[4,5]$, while in those who are symptomatic, the fibroid growth may compress the endometrium, nerves, and surrounding organs, causing discomfort, inconvenience $[6,7]$, and impaired quality of life $[8,9]$. Tumors may also cause infertility, pregnancy loss, and placental abruption.

Symptomatic uterine fibroids generally require surgical intervention, such as hysterectomy and myomectomy [10]. However, these invasive treatments are not popular choices among women, who often delay treatment by 5 years on average, and prefer uterine-conserving procedures [9]. Noninvasive high-intensity focused ultrasound (HIFU) ablation has emerged as an alternative option to surgery for uterine fibroids, offering minimal invasiveness without an incision that can be performed as a uterine-conserving outpatient treatment in most types of uterine fibroids [11-14]. Compared to the uterine artery embolization, another minimalinvasive treatment option, HIFU is preferred if clinicians and patients have concerns for low vascularity fibroids, high risk for anesthesia/sedation, radiation exposure, impaired 
renal function, allergy to iodine contrast medium, bleeding tendency, or difficult vascular access [15-17]. Localized ablation is achieved by concentrating acoustic waves at a focal point to cause heat and raise focal temperature to over $55^{\circ} \mathrm{C}$, without affecting the surrounding tissues $[18,19]$. This energy transmission causes coagulative necrosis, resulting in resorption and shrinkage of the ablated tumor. Two well-known image guidance methods are coupled with the HIFU system; ultrasound guidance (USgHIFU) and magnetic resonance guidance (MRgHIFU). Several USgHIFU systems are commercially available, but their widespread adoption is limited by the lack of thermal monitoring and high-resolution images for precise positioning. The realtime thermal monitoring and high-quality imaging provided by MRgHIFU ensures its superiority over USgHIFU, but MRgHIFU may be limited by the operation and specific requirements of different MRI systems. Another limitation of most marketed HIFU systems is that they require patients to remain prone for several hours during the procedure, which is not only uncomfortable for them but also increases their risk of skin burns.

The novel MRgHIFU system (the ArcBlate focused ultrasound ablation system) addresses these limitations by combining an arc-shaped treatment machine (an upgrade of the present MRI table) with an automated 3-dimensional navigation along the patient's abdomen in the supine position and an intuitive graphical user interface (GUI) real-time thermal monitoring tool. This study planned to evaluate the feasibility and safety of the ArcBlate focused ultrasound ablation system for the treatment of uterine fibroids.

\section{Materials and methods}

This study was approved by Taiwan's Food and Drug Administration (TFDA) and the Institutional Review Board of BLINDED INFORMATION (BLINDED INFORMATION; reference number: 104-4660A) and was conducted in accordance with the Declaration of Helsinki Ethical Principles and Good Clinical Practices. Each subject gave a written informed consent form. The datasets used and analyzed during the current study were available from the corresponding author on reasonable request.

\section{ArcBlate focused ultrasound ablation system}

The first prototype of the ArcBlate focused ultrasound ablation system was developed by the Department of Biomedical Engineering in the National Health Research Institute (NHRI), which initially tested the prototype in 7 mini pigs between 2009 and 2011, then conducted a pilot study involving 6 patients with uterine fibroids in BLINDED INFORMATION in 2015 (NCT02283502). EpiSonica undertook subsequent development and manufacture from 2014 and finished this study.

In contrast to other commercially available MRgHIFU systems, the ArcBlate focused ultrasound ablation system (100 M, manufactured by EpiSonica Corporation, Hsinchu, Taiwan) consists of three parts; a special portable arc for anchoring the ultrasound detector, a control cabinet, and a control console. Figure 1 shows the placement of the ArcBlate system. The portable ARC is designed for easy attachment to the MR patient table and can perform a

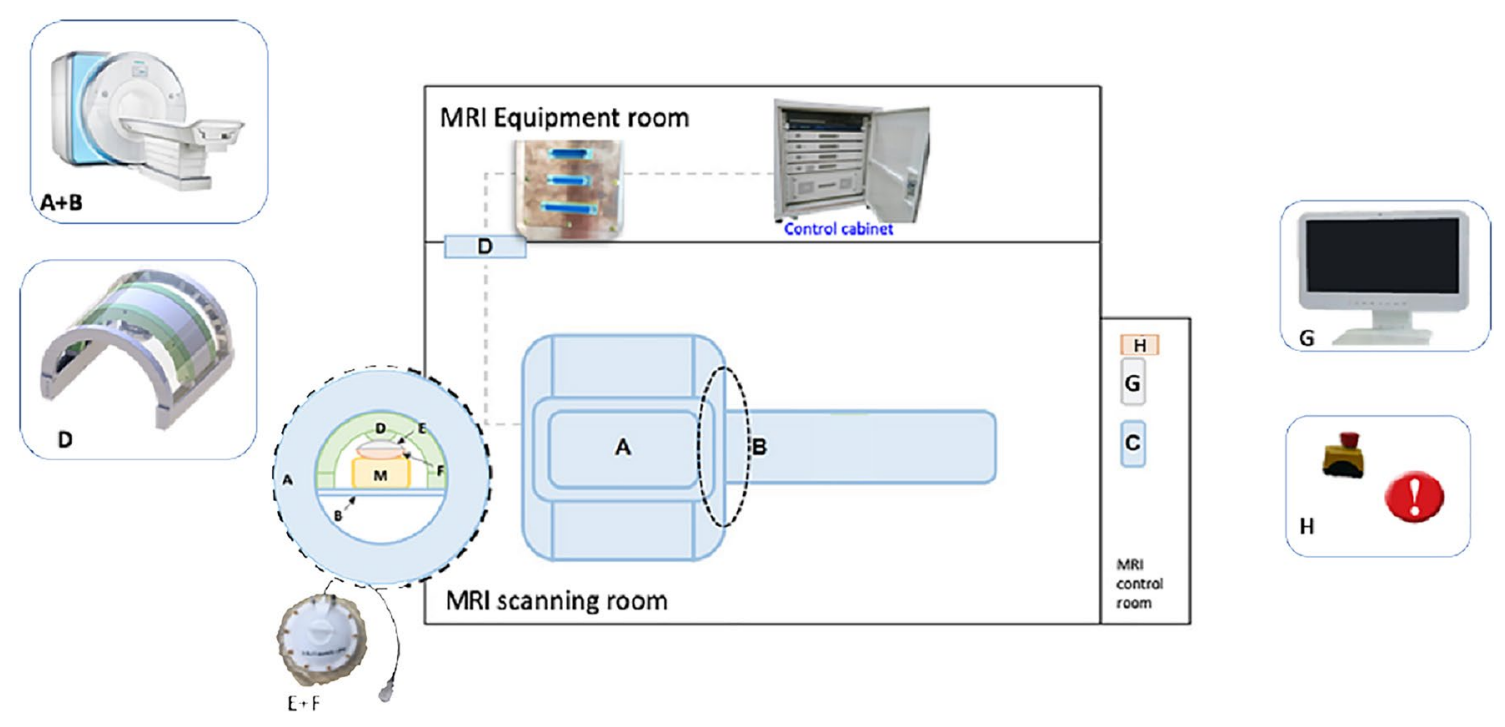

Fig. 1 Placement of the ArcBlate system. A MRI. B Patient table. C MRI console. D Portable ARC. E, F HIFU transducer and the water bag. G HIFU console. H Emergency stop 
three-dimensional movement of $20 \mathrm{~cm}$ horizontally along the patient table (longitudinal axis), allowing for $\mathrm{a} \leq 20^{\circ}$ shift along the arc (horizontal axis) and $\leq 20^{\circ}$ rotation, in combination with a one-dimensional ArcBlate transducer to allow vertical movements to depths of 6-20 cm. A 15 -channel annular array transducer integrated with a flexible water bag was designed for mounting on the portable ARC for generating high-intensity focused ultrasound energy. The flexible water bag is filled with degassed water and is in direct contact with the patient's skin to enable propagation of the ultrasound beam to the target tumor. The positioning of the portable ARC and the ultrasonic energy delivered by the HIFU transducer is controlled by the console through the control cabinet.

\section{Patients}

Ten patients, including nine with uterine fibroids and one with adenomyosis, were enrolled. Inclusion criteria were (1) benign uterine tumor, such as uterine fibroids, adenomyoma, or adenomyosis; (2) tumor size between 4 and $15 \mathrm{~cm}$ or an adenomyosis area larger than $4 \mathrm{~cm}$; (3) age $>20$ years and scheduled for a hysterectomy; (4) abdominal circuit under $100 \mathrm{~cm}$. Exclusion criteria were (1) pregnancy; (2) hemoglobin below $9 \mathrm{~g} / \mathrm{dL}$; (3) other pelvic diseases; (4) unsuitable HIFU beam path; (5) MRI contraindications; (6) medical history of calcified gynecologic tumor; (7) co-existing diseases including heart, vascular, or renal; (8) malignant uterine tumors identified by MRI; (9) failure to satisfy study enrollment criteria after an assessment by an expert gynecologist and/or radiologist.

The diagnostic criteria for adenomyosis using MRI included (1) low signal intensity of myometrium, with indistinct margins and (2) diffuse or focal junctional zone exceeding $12 \mathrm{~mm}$ [20].

\section{Pretreatment screening and preparation}

Before treatment, all subjects underwent routine blood testing and quality of life assessment by the 36-Item Short Form 36 Health Survey (SF-36) questionnaire. MRI was performed within 30 days of these testing procedures using the $3 \mathrm{~T}$ Trio MRI scanner (Siemens Healthcare, Erlangen, Germany).

Standard T2-weighted imaging using three orthogonal planes (i.e., coronal, sagittal, and transverse) assigned the Funaki classification and evaluated the size, volume, location, and status of the benign uterine tumor. Standard T1-weighted imaging identified the benign or malignant uterine tumor after the intravenous administration of a gadolinium-based contrast agent (Magnevist, Bayer Pharma AG, Berlin, Germany; dose: $0.2 \mathrm{~mL} / \mathrm{kg}$ ). Other pre-procedural preparations included an 8 -h fasting period and enema administrations to exclude air and other possible obstacles (e.g., bowel loops anterior to the uterus), and abdominal and pubic hair shaving to allow the skin to connect with the ultrasound beam closely to prevent the skin burn [21-23]. Bladder filling was conducted only if the fibroid location was close to the intestinal tract.

\section{MRgHIFU treatment}

The patient was placed on the MRI table in the supine position. The portable ARC was put on the MRI table and the water bag was placed in direct contact with the patient's abdominal skin. Sterile ultrasound gel was applied to the contact area to eliminate air gaps between the water bag and the patient's skin surface. A quick T2-weighted MR image in the sagittal plane was acquired to confirm the absence of air bubbles between the water bag and the patient's skin surface.

Subsequently, high-resolution MR images in three orthogonal planes for treatment planning were acquired using a T2-weighted turbo-spin echo sequence with the following parameters: variable TR depending on different planes and/ or different patients, $\mathrm{TE}=120 \mathrm{~ms}$, flip angle $=120$ degrees, matrix size $=512 \times 358$, field of view $(F O V)=384 \times 384$ $\mathrm{mm}^{2}$, and slice thickness $=4 \mathrm{~mm}$ without gaps. These MR images were displayed on the ArcBlate user control GUI, software contained inside the control console designed to assist the physician with establishing the treatment plan based on the tumor characteristics and to identify critical organs such as the bladder, bowel, and spine surrounding the targeted fibroids.

At the treatment planning stage, a single-point treatment pattern, six square-shaped treatment patterns consisting of treatment points (i.e., 4 and 9 points), and gap distances (i.e., 3,6 , or $10 \mathrm{~mm}$ gap) were manually selected and inserted in the coronal plane of the T2-weighted MR images. These different treatment patterns helped the physician establish the treatment plan for each patient. Moreover, the power (i.e., $120-300 \mathrm{~W}$ ), ablation time (i.e., 10-60 s), and cooling time (i.e., 5-60 s) were defined for each treatment pattern. Based on the individual variability, several test sonications with low energy using a single-point treatment pattern were performed in the center of the targeted fibroid on the deeper MR coronal plane to verify the location of heating and to determine the power level for ablation. The treatment plan for each patient was established slice-by-slice from a deeper MR coronal plane, and the planned treatment pattern in each slice was put within a 10-mm distance away from the margin of the targeted fibroid. The planned treatment tumor volume was up to $50 \%$ of the fibroid according to safety considerations defined by the TFDA and treatment time was kept to within $1-2 \mathrm{~h}$.

The treatment dose was measured with the following formula: 
Treatment dose $(J)=\sum$ Power $(W) \times$ Number of treatment points in a treatment pattern $\times$ Ablation time $(\sec )$

During the treatment, the ArcBlate transducer was mounted under the portable ARC and automatically moved to the planned treatment location mapped out in the patient's treatment plan. Real-time thermal monitoring was also performed in three adjacent coronal slices, using a fast spoiled gradient-recalled-echo sequence with the following parameters: $\mathrm{TR}=11 \mathrm{~ms}, \mathrm{TE}=7 \mathrm{~ms}$, flip angle $=30$ degrees, matrix size $=128 \times 128$, FOV $=384 \times 384 \mathrm{~mm}^{2}$, slice thickness $=4 \mathrm{~mm}$ with a $4 \mathrm{~mm}$ gap, number of slices $=3$ with the center slice placed at the planned treatment plane, and temporal resolution $=4.2 \mathrm{~s} /$ dynamic. Following thermal imaging scanning, 3 dynamics were performed and then the sonications began. Thermal imaging continued to scan more than 10 dynamics after the sonication stopped. These temperature maps were calculated from raw data centered in the k-space that of the myometrium and higher than that of the skeletal muscle), or type 3 (high; equal to or higher than that of the myometrium). This classification has been adopted in clinical practices at most institutions performing MR-guided HIFU ablation.

Tumor volume was calculated with the following formula:

Tumor volume $\left(\mathrm{cm}^{3}\right)=\frac{1}{6} \pi \cdot d_{1}(\mathrm{~cm}) \cdot d_{2}(\mathrm{~cm}) \cdot d_{3}(\mathrm{~cm})$

where $\pi$ equals 3.14 , and $d_{1}, d_{2}$, and $d_{3}$ equal the longest diameter in three orthogonal planes (i.e., coronal, sagittal, and transverse) of the benign uterine tumor measured on the T2-weighted MR images. Treatment effect was measured by fibroid shrinkage using T2-weighted MR images.

Shrinkage of the tumor volume was calculated with the following formula:

Shrinkage $(\%)=\frac{\text { Tumor volume after treatment }\left(\mathrm{cm}^{3}\right)-\text { Tumor volume before volume }\left(\mathrm{cm}^{3}\right)}{\text { Tumor volume before treatment }\left(\mathrm{cm}^{3}\right)} \times 100$

matrix and based on the proton resonance frequency shift $[24,25]$, and then displayed on the ArcBlate user control GUI to assist the physician to monitor temperature changes in the focal, near, and far fields along the ultrasound beam axis.

No patients required sedation, anesthesia, a urinary catheter, or MRI contrast agent. At the end of the treatment, patients were monitored for at least one hour for the occurrence of any acute adverse events.

\section{Post-treatment follow-up}

After discharge, patients were followed-up by a telephone call at 1 week for the assessment of postoperative adverse events. At 1 and 3 months after treatment, quality of life was assessed with the SF-36 questionnaire and tumor volume was determined by MRI.

\section{Assessments and data analysis}

Classification of the benign uterine tumor by fibroid (i.e., subserosal, intramural, submucosal, or adenomyosis) and Funaki type was based on the signal intensity of the T2-weighted MR images [26], in the judgment of one of the investigators (G.G.L., with 15 years of experience in analyzing gynecological MRI images). The Funaki classification evaluates uterine fibroids as either type 1 (low; comparable to that of skeletal muscle), type 2 (intermediate; lower than
The SF-36 questionnaire was used for evaluating quality of life as described in the previous research. Higher scores indicated better quality of life [27].

\section{Results}

Ten patients were enrolled in this study. The median age was 44 years (range 34-49 years). Of them, four had subserosal myomas, three had intramural myomas, two had submucosal myomas, and one had diffuse adenomyosis. The fibroids were classified as Funaki type $1(n=4)$, type 2 $(n=3)$, and type $3(n=2)$. Before treatment, the mean fibroid volume was $273.4 \pm 32.10 \mathrm{~cm}^{3}$ for subserosal myomas, $371.0 \pm 107.74 \mathrm{~cm}^{3}$ for intramural myomas, $108.8 \pm 23.50$ $\mathrm{cm}^{3}$ for submucosal myomas (Table 1), and $379.5 \mathrm{~cm}^{3}$ for adenomyosis (data not shown). The average treatment time for myoma was $29.6 \mathrm{~min}$ (range 11.5-57.3 $\mathrm{min}$ ) and the treatment time for adenomyosis was $55 \mathrm{~min}$.

At 3 months after treatment, the mean shrinkage ratio was $12.56 \pm 6.49 \%$. MRgHIFU treatment reduced fibroid size in seven patients (subserosal $n=3$; intramural $n=2$; submucosal $n=1$; diffuse adenomyosis $n=1$ ); one subserosal case experienced a slight increase of $5.42 \%$ in fibroid size. The mean extent of tumor shrinkage was $7.6 \pm 6.01 \%$ in the subserosal myomas, $25.2 \pm 17.53 \%$ in the intramural myomas, $3.6 \pm 3.58 \%$ in the submucosal myomas (Table 2), and $5.5 \%$ for the adenomyosis case (data not shown), while the 
Table 1 Treatment outcome and disease characteristics of each patient

\begin{tabular}{|c|c|c|c|c|c|c|c|c|c|c|}
\hline \multirow[t]{2}{*}{ Case } & \multirow[t]{2}{*}{ Fibroid type } & \multirow[t]{2}{*}{ Funaki type } & \multicolumn{3}{|c|}{ Tumor volume $\left(\mathrm{cm}^{3}\right)$} & \multicolumn{2}{|c|}{ Shrinkage (\%) } & \multicolumn{3}{|l|}{ SF-36 score } \\
\hline & & & Pretreatment & $\begin{array}{l}\text { 1-Month } \\
\text { follow-up }\end{array}$ & $\begin{array}{l}\text { 3-Month } \\
\text { follow-up }\end{array}$ & $\begin{array}{l}\text { 1-Month } \\
\text { follow-up }\end{array}$ & $\begin{array}{l}\text { 3-Month } \\
\text { follow-up }\end{array}$ & Pretreatment & $\begin{array}{l}\text { 1-Month } \\
\text { follow-up }\end{array}$ & $\begin{array}{l}\text { 3-Month } \\
\text { follow-up }\end{array}$ \\
\hline 01 & Subserosal & 2 & 191.8 & 163.1 & 202.2 & 14.96 & -5.42 & 87 & 83 & 89 \\
\hline 02 & Subserosal & 1 & 348.6 & 380.6 & 347.1 & -9.18 & 0.43 & 77 & 83 & 84 \\
\hline 03 & Subserosal & 1 & 280.6 & 244.5 & 225.5 & 12.87 & 19.64 & 75 & 79 & 83 \\
\hline 04 & Intramural & 3 & 525.6 & 298.2 & 216.2 & 43.26 & 58.87 & 81 & 83 & 83 \\
\hline 05 & Subserosal & 1 & 272.5 & 266.3 & 229.5 & 2.28 & 15.78 & 70 & 75 & 77 \\
\hline 06 & Intramural & 2 & 423.7 & 338.4 & 353.4 & 20.13 & 16.59 & 87 & 90 & 83 \\
\hline 07 & Submucosal & 3 & 132.3 & 177.2 & 132.3 & -33.94 & 0.00 & 67 & 77 & 49 \\
\hline 08 & Submucosal & 1 & 85.3 & 90.2 & 79.2 & -5.74 & 7.15 & 76 & 58 & 53 \\
\hline 09 & Intramural & 2 & 163.7 & 163.7 & 163.7 & 0.00 & 0.00 & 75 & 60 & 74 \\
\hline
\end{tabular}

SF-36: 36-Item Short Form Survey

Table 2 Treatment outcomes summarized by fibroid type

\begin{tabular}{cccc}
\hline & $\begin{array}{l}\text { Subserosal myoma } \\
\mathrm{N}=4\end{array}$ & $\begin{array}{l}\text { Intramural myoma } \\
\mathrm{N}=3\end{array}$ & $\begin{array}{l}\text { Submucosal myoma } \\
\mathrm{N}=2\end{array}$ \\
\hline $\begin{array}{l}\text { Tumor volume }\left(\mathrm{cm}^{3}\right) \\
\text { Pretreatment }\end{array}$ & $273.4 \pm 32.10$ & $371.0 \pm 107.74$ & $108.8 \pm 23.50$ \\
1-month follow-up & $263.6 \pm 44.87$ & $266.8 \pm 52.82$ & $133.7 \pm 43.50$ \\
3-month follow-up & $251.1 \pm 32.57$ & $244.4 \pm 56.55$ & $105.8 \pm 26.55$ \\
Shrinkage (\%) & & & $-19.8 \pm 14.10$ \\
1-month follow-up & $5.2 \pm 5.55$ & $21.1 \pm 12.50$ & $3.6 \pm 3.58$ \\
3-month follow-up & $7.6 \pm 6.01$ & $25.2 \pm 17.53$ & $71.7 \pm 4.71$ \\
Total SF-36 score & & & $67.4 \pm 9.83$ \\
Pretreatment & $77.2 \pm 3.44$ & $80.8 \pm 3.37$ & $51.0 \pm 1.74$ \\
1-month follow-up & $80.1 \pm 2.08$ & $77.6 \pm 9.13$ & $80.0 \pm 3.18$ \\
3-month follow-up & $83.2 \pm 2.47$ & & \\
\hline
\end{tabular}

SF-36: 36-Item Short Form Survey

highest shrinkage ratio by Funaki classification was in type 3 fibroids, followed by type 1 and lastly type 2 ; some of the type 2 fibroids increased in volume after treatment (Table 3).

Most patients showed stable or improved SF-36 scores over 3 months of follow-up. The mean SF-36 score was $77.2 \pm 3.44$ before treatment and 83.2 \pm 2.47 at 3 months for the subserosal myoma cohort; corresponding values were $80.8 \pm 3.37$ and $80.0 \pm 3.18$, respectively, for the intramural myoma cases (Table 2). In contrast, SF-36 scores fell over time in submucosal myoma cases, from $71.7 \pm 4.71$ points at baseline to $51.0 \pm 1.74$ points at 3 months. SF-36 scores were stable over time for fibroids classified by Funaki type: the mean SF-36 score was $74.7 \pm 1.53$ before treatment and $74.2 \pm 7.32$ at 3 months for type $1 ; 82.7 \pm 3.89$ and $81.9 \pm 4.43$, respectively, for type 2 ; and $74.0 \pm 6.69$ and $66.2 \pm 16.97$, respectively, for type 3 (Table 3 ). The adenomyosis case experienced an improvement of 6 points in SF-36 score at 3 months (baseline: 63; 3 months: 69; data not shown). During the
3 months of follow-up, all participants completed the treatment without common complications or adverse effects, including skin burn and abdominal pain, abdominal wall edema, bladder wall injury, vaginal discharge, and sacral bone edema.

\section{Discussion}

The application of HIFU as the treatment for uterine fibroids has been studied for many years and is now considered an appropriate alternative therapy for patients who do not respond to conservative treatments. Despite the non-invasive feature of HIFU, many limitations related to technique and mechanical design have prevented its widespread application [22, 28].

Current MRgHIFU treatment protocols suggest an ablation rate (i.e., nonperfused volume [NPV] ratio) of $70-80 \%$ to achieve the desired treatment outcomes [21, 
Table 3 Treatment outcomes summarized by Funaki type

\begin{tabular}{llll}
\hline & $\begin{array}{l}\text { Funaki type 1 } \\
\mathrm{N}=4\end{array}$ & $\begin{array}{l}\text { Funaki type 2 } \\
\mathrm{N}=3\end{array}$ & $\begin{array}{l}\text { Funaki type 3 } \\
\mathrm{N}=2\end{array}$ \\
\hline $\begin{array}{l}\text { Tumor volume }\left(\mathrm{cm}^{3}\right) \\
\text { Pretreatment }\end{array}$ & $246.8 \pm 56.46$ & $259.7 \pm 82.38$ & $329.0 \pm 196.65$ \\
$\begin{array}{l}\text { 1-month follow- } \\
\text { up }\end{array}$ & $245.4 \pm 59.72$ & $221.7 \pm 58.33$ & $237.7 \pm 60.50$ \\
$\begin{array}{l}\text { 3-month follow- } \\
\text { up }\end{array}$ & $220.3 \pm 54.85$ & $239.8 \pm 57.89$ & $174.3 \pm 41.95$ \\
$\begin{array}{l}\text { Shrinkage (\%) } \\
\text { 1-month follow- } \\
\quad \text { up }\end{array}$ & $0.1 \pm 4.90$ & $11.7 \pm 6.04$ & $4.7 \pm 38.60$ \\
3-month follow- & $10.7 \pm 4.32$ & $3.7 \pm 6.62$ & $29.4 \pm 29.44$ \\
$\quad$ up & & & \\
$\begin{array}{l}\text { Total SF-36 score } \\
\text { Pretreatment }\end{array}$ & $74.7 \pm 1.53$ & $82.7 \pm 3.89$ & $74.0 \pm 6.96$ \\
1-month follow- & $73.6 \pm 5.65$ & $77.7 \pm 9.15$ & $80.2 \pm 3.00$ \\
$\quad$ up & & & \\
3-month follow- & $74.2 \pm 7.32$ & $81.9 \pm 4.43$ & $66.2 \pm 16.97$ \\
$\quad$ up & & & \\
\hline
\end{tabular}

SF-36: 36-Item Short Form Survey
29]. In our study, we complied with the TFDA's safety considerations to produce an NPV ratio of under $50 \%$, which led to a mean fibroid volume reduction rate of $12.56 \pm 6.49 \%$ at 3 months of follow-up. The effectiveness of ArcBlate MRgHIFU seemed not to be inferior to that of other MRgHIFU systems, which demonstrated mean fibroid volume shrinkage rates of $12.6-18.1 \%$ at 3 months [30, 31].

A higher NPV ratio was found to be correlated with greater tumor volume shrinkage. Keserci et al. discovered that if the NPV achieved a ratio of at least $90 \%$, the mean fibroid reduction ratio would be as high as $54 \pm 13 \%$ [31]. A report of 80 patients with leiomyoma suggested that a larger NPV ratio would result in greater shrinkage and improved relief of symptoms [32]. Although we performed an NPV ratio of under $50 \%$ per TFDA recommendations, future research is warranted to find a best NPV ratio with balanced therapeutic efficacy and safety.

Regardless of the low NPV ratio, one intramural case in our study demonstrated an astonishing mass reduction of $58.8 \%$ at 3 months after the treatment. According to the
Fig. 2 T2-weighted MR images of case no. 4, a 49-year-old woman with Funaki type 1 within the Funaki type 3 fibroid. Images include pretreatment (a, b) and post-treatment threemonth follow-up $(\mathbf{c}, \mathbf{d})$. The pre-treated volume of fibroid was $525.6 \mathrm{~cm}^{3}$, and the posttreated volume was $216.2 \mathrm{~cm}^{3}$, with a shrinkage rate of $58.87 \%$. Sagittal view: (a, c); axial view: $(\mathbf{b}, \mathbf{d})$. Red circles were the area of Funaki type 3 uterine fibroid; green arrows were the area of Funaki type 1 uterine fibroid
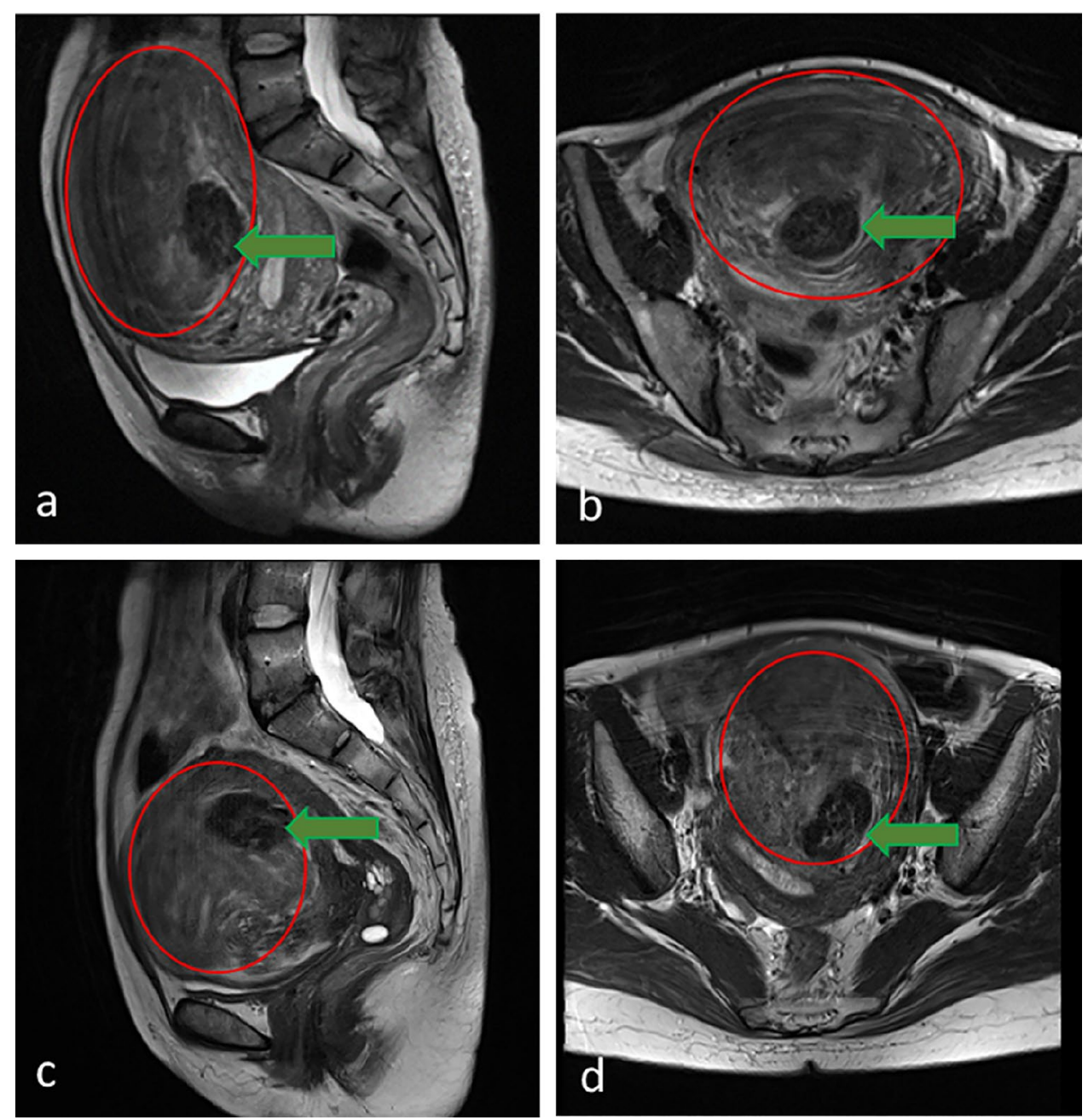
literature, treating Funaki type 3 fibroid tissue by HIFU is difficult because of high vascularization which results in decreasing therapeutic effects of heating [23, 33, 34], yet our intramural case was identified to be Funaki type 3. During treatment, her physician found a solid area with fibroid tissue similar to Funaki type 1 within the Funaki type 3 fibroid (Fig. 2). The treatment plan was to focus mainly on the type 1-like tissue, yet an overall mass reduction was observed. The treatment effect may be attributed to the accelerated metabolism of ablated tissue by rich vascularity, which may have influenced the surrounding mass. Despite the decreased estrogen level in this patient (49 years) who approached menopause may also have influenced the treatment outcome [35], our result still suggests a new approach toward a more efficient treatment of mixed fibroid presentation.

No real-time monitoring in thermal damage in tissue was one of the limitations in ultrasonography-guided HIFU therapy [36], while it could be resolved under MR guidance. Besides, patients having pelvic endometriosis, adhesions locating between the uterus and bowel, or $>10-\mathrm{mm}$ abdominal surgical scar are not recommended to receive HIFU therapy [37]. However, one patient with adenomyosis in our study showed a lower shrinkage rate after 3 months than another study (our study vs. another study: $5.5 \%$ vs. $46.3 \%$ ) [38]. Possible reasons for different shrinkage rates might include the treated volume limited in the current study (no more than 50\%), different lesion type (current study vs. Jeng et al.'s study: diffuse vs. focal/regional), and study design (prospective vs. retrospective). However, it should be interpreted with caution due to the small sample size.

Moreover, we observed that the fibroid size in some patients became larger at 1-month follow-up after HIFU therapy. Transient inflammatory or congestive response caused by HIFU possibly leads to increase the fibroid size at acute phase, and size shrinkage was observed in the 3-month follow-up. A longitudinal study to assess the inflammatory response to HIFU is warranted.

[39] Considering the treatment outcome among patients by Funaki classification, quality of life scores in the type 3 cohort seemed to decrease slightly after the treatment, despite these fibroids demonstrating considerable reductions in size at 3 months (mean shrinkage: $29.4 \% \pm 29.44$ ). In contrast, quality of life for the Funaki type 1 and 2 cohorts was much more stable, despite lacking remarkable reductions in tumor size (mean shrinkage: type $1,10.7 \% \pm 4.32$; type 2 , $3.7 \% \pm 6.62$ ). The better quality of life score of Funaki type 1 and 2 groups before treatment may have influenced physical and mental health status after treatment. Also, the results may be biased by the small sample size. Further large-scale investigations are warranted to validate our findings.

The most common adverse effect of HIFU treatment is skin burn [30, 39]; none of our patients reported this effect through 3 months of follow-up. Use of the soft water bag may have reduced the risks of skin burn by fitting the abdominal contour, binding with the HIFU transducer, and moving with the transducer to ensure direct skin contact. Another potential protective mechanism against skin burns is that putting the patient in the supine position allows for accurate monitoring of irregularities on the abdominal surface.

Much research has shown that rectal and bladder filling are very useful practices for avoiding adverse effects and for mitigating bowel-related side effects after MRgHIFU treatment [40, 41]. Except for the fibroid location of patients be close to the intestinal tract, we did not follow these practices in our study, because they can be uncomfortable for patients. In addition, endometrial ablation has been used to treat submucosal fibroids [42] but it may cause severe endometrial impairment and reduce possibilities of future pregnancy [43]. We therefore did not ablate the endometrium during treatment, to prevent any adverse consequences regarding future pregnancy.

\section{Conclusion}

Although this was a feasibility study in a small population, the effectiveness and safety of ArcBlate MRgHIFU were investigated in a wide range of patient characteristics. Our system demonstrated clinical effects similar to those demonstrated by other MRgHIFU systems and it proved to be safe. ArcBlate MRgHIFU has the potential to be an alternative, non-invasive treatment option for uterine benign tumors.

Acknowledgements This study was supported by grants from Chang Gung Medical Foundation (CMRPG3K0541 and XMRPG3D0871).

Author contributions CJW and GL conceived and designed the study. CHW, YYS, YSL, and KSM conducted the study and collected data. YTH conducted the analyses. CJW drafted the manuscript. GL and KYW conducted literature review. All authors interpreted the data and revised the manuscript. All authors read and approved the final manuscript.

Funding This study received research grants from Chang Gung Medical Foundation (CMRPG3K0541 and XMRPG3D0871).

Data availability The data shown in this study are available on request from the corresponding author.

\section{Declarations}

Conflict of interest All the authors declare that they have no competing interests. 
Ethical approval This study was approved by the Institutional Review Board (IRB) of Linkou Chang Gung Memorial Hospital (CGMHLK; Reference Number: 104-4660A) and was conducted in accordance with the Declaration of Helsinki Ethical Principles and Good Clinical Practices.

Consent to participate After the IRB approval, this study obtained the written informed consent forms from subjects.

Consent for publication After the IRB approval, this study acquired the written informed consent forms from subjects who agreed that their data were published.

Open Access This article is licensed under a Creative Commons Attribution 4.0 International License, which permits use, sharing, adaptation, distribution and reproduction in any medium or format, as long as you give appropriate credit to the original author(s) and the source, provide a link to the Creative Commons licence, and indicate if changes were made. The images or other third party material in this article are included in the article's Creative Commons licence, unless indicated otherwise in a credit line to the material. If material is not included in the article's Creative Commons licence and your intended use is not permitted by statutory regulation or exceeds the permitted use, you will need to obtain permission directly from the copyright holder. To view a copy of this licence, visit http://creativecommons.org/licenses/by/4.0/.

\section{References}

1. Prayson RA, Hart WR (1995) Pathologic considerations of uterine smooth muscle tumors. Obstetrics and gynecology clinics of North America 22:637-657.

2. Stewart EA (2001) Uterine fibroids. The Lancet 357:293-298.

3. Wise LA, Laughlin-Tommaso SK (2016) Epidemiology of Uterine Fibroids: From Menarche to Menopause. Clinical obstetrics and gynecology 59:2-24. http://https://doi.org/10.1097/GRF.00000 00000000164.

4. Okolo S (2008) Incidence, aetiology and epidemiology of uterine fibroids. Best Pract Res Clin Obstet Gynaecol 22:571-588. http://https://doi.org/10.1016/j.bpobgyn.2008.04.002.

5. Schwartz SM, Marshall LM, Baird DD (2000) Epidemiologic contributions to understanding the etiology of uterine leiomyomata. Environ Health Perspect 108 Suppl 5:821-827. http://https://doi. org/10.1289/ehp.00108s5821.

6. Sue W, Sarah S-B (2009) Radiological appearances of uterine fibroids. The Indian journal of radiology \& imaging 19:222.

7. Parker WH (2007) Etiology, symptomatology, and diagnosis of uterine myomas. Fertility and sterility 87:725-736.

8. Downes E, Sikirica V, Gilabert-Estelles J et al (2010) The burden of uterine fibroids in five European countries. Eur J Obstet Gynecol Reprod Biol 152:96-102. http://https://doi.org/10.1016/j. ejogrb.2010.05.012.

9. Borah BJ, Nicholson WK, Bradley L et al (2013) The impact of uterine leiomyomas: a national survey of affected women. American journal of obstetrics and gynecology 209:319.e311-319.e320. http://https://doi.org/10.1016/j.ajog.2013.07.017.

10. Havryliuk Y, Setton R, Carlow JJ et al (2017) Symptomatic Fibroid Management: Systematic Review of the Literature. Jsls 21. http://https://doi.org/10.4293/jsls.2017.00041.

11. Jones S, O'Donovan P, Toub D (2012) Radiofrequency ablation for treatment of symptomatic uterine fibroids. Obstet Gynecol Int 2012:194839. http://https://doi.org/10.1155/2012/194839.
12. Bongers M, Brölmann H, Gupta J et al (2015) Transcervical, intrauterine ultrasound-guided radiofrequency ablation of uterine fibroids with the VizAblate ${ }^{\circledR}$ System: three- and six-month endpoint results from the FAST-EU study. Gynecol Surg 12:61-70. http://https://doi.org/10.1007/s10397-014-0873-1.

13. Brölmann H, Bongers M, Garza-Leal JG et al (2016) The FASTEU trial: 12-month clinical outcomes of women after intrauterine sonography-guided transcervical radiofrequency ablation of uterine fibroids. Gynecol Surg 13:27-35. http://https://doi.org/10. 1007/s10397-015-0915-3.

14. Toub DB (2017) A New Paradigm for Uterine Fibroid Treatment: Transcervical, Intrauterine Sonography-Guided Radiofrequency Ablation of Uterine Fibroids with the Sonata System. Curr Obstet Gynecol Rep 6:67-73. http://https://doi.org/10.1007/ s13669-017-0194-2.

15. Sieroń D, Wiggermann P, Skupiński J et al (2011) Uterine artery embolisation and magnetic resonance-guided focused ultrasound treatment of uterine fibroids. Polish journal of radiology 76:37-39.

16. Jeong J-H, Hong GP, Kim Y-R et al (2016) Clinical Consideration of Treatment to Ablate Uterine Fibroids with Magnetic Resonance Imaging-guided High Intensity Focused Ultrasound (MRgFUS): Sonalleve. Journal of menopausal medicine 22:94-107. http://https://doi.org/10.6118/jmm.2016.22.2.94.

17. Leonhardt H, Aziz A, Lönn L (2005) Post-embolization syndrome and complete expulsion of a leiomyoma after uterine artery embolization. Acta Obstetricia et Gynecologica Scandinavica 84:303305. http://https://doi.org/10.1111/j.0001-6349.2005.0358d.x.

18. Rabkin BA, Zderic V, Crum LA et al (2006) Biological and physical mechanisms of HIFU-induced hyperecho in ultrasound images. Ultrasound in medicine \& biology 32:1721-1729.

19. ter Haar G, Coussios C (2007) High intensity focused ultrasound: physical principles and devices. International Journal of Hyperthermia 23:89-104.

20. Cunningham RK, Horrow MM, Smith RJ et al (2018) Adenomyosis: A Sonographic Diagnosis. RadioGraphics 38:1576-1589. http://https://doi.org/10.1148/rg.2018180080.

21. Fennessy FM, Tempany CM, McDannold NJ et al (2007) Uterine leiomyomas: MR imaging-guided focused ultrasound surgeryresults of different treatment protocols. Radiology 243:885-893.

22. Tempany CM, Stewart EA, McDannold N et al (2003) MR imaging-guided focused ultrasound surgery of uterine leiomyomas: a feasibility study. Radiology 226:897-905.

23. Funaki K, Sawada K, Maeda F et al (2007) Subjective effect of magnetic resonance-guided focused ultrasound surgery for uterine fibroids. Journal of Obstetrics and Gynaecology Research 33:834-839.

24. Hindman J (1966) Proton resonance shift of water in the gas and liquid states. The Journal of Chemical Physics 44:4582-4592.

25. Peters RT, Hinks RS, Henkelman RM (1998) Ex vivo tissue-type independence in proton-resonance frequency shift MR thermometry. Magnetic resonance in medicine 40:454-459.

26. Funaki K, Fukunishi H, Funaki T et al (2007) Magnetic resonance-guided focused ultrasound surgery for uterine fibroids: relationship between the therapeutic effects and signal intensity of preexisting T2-weighted magnetic resonance images. American journal of obstetrics and gynecology 196:184. e181-184. e186.

27. Brazier JE, Harper R, Jones NM et al (1992) Validating the SF-36 health survey questionnaire: new outcome measure for primary care. Bmj 305:160-164. http://https://doi.org/10.1136/bmj.305. 6846.160 .

28. Lee J-S, Hong G-Y, Park B-J et al (2015) Ultrasound-guided highintensity focused ultrasound treatment for uterine fibroid \& adenomyosis: a single center experience from the Republic of Korea. Ultrasonics sonochemistry 27:682-687. 
29. LeBlang SD, Hoctor K, Steinberg FL (2010) Leiomyoma shrinkage after MRI-guided focused ultrasound treatment: report of 80 patients. American Journal of Roentgenology 194:274-280.

30. Cheung VYT (2018) High-intensity focused ultrasound therapy. Best Pract Res Clin Obstet Gynaecol 46:74-83. http://https://doi. org/10.1016/j.bpobgyn.2017.09.002.

31. Keserci B, Duc NM (2018) Magnetic Resonance Imaging Parameters in Predicting the Treatment Outcome of High-intensity Focused Ultrasound Ablation of Uterine Fibroids With an Immediate Nonperfused Volume Ratio of at Least 90. Acad Radiol 25:1257-1269. http://https://doi.org/10.1016/j.acra.2018.01.022.

32. LeBlang SD, Hoctor K, Steinberg FL (2010) Leiomyoma shrinkage after MRI-guided focused ultrasound treatment: report of 80 patients. AJR Am J Roentgenol 194:274-280. http://https://doi. org/10.2214/ajr.09.2842.

33. Funaki K, Fukunishi H, Funaki T et al (2007) Magnetic resonance-guided focused ultrasound surgery for uterine fibroids: relationship between the therapeutic effects and signal intensity of preexisting T2-weighted magnetic resonance images. Am J Obstet Gynecol 196:184.e181-186. http://https://doi.org/10.1016/j.ajog. 2006.08.030

34. Suomi V, Komar G, Sainio T et al (2019) Comprehensive feature selection for classifying the treatment outcome of highintensity ultrasound therapy in uterine fibroids. Sci Rep 9:10907. http://https://doi.org/10.1038/s41598-019-47484-y.

35. Rein MS, Barbieri RL, Friedman AJ (1995) Progesterone: a critical role in the pathogenesis of uterine myomas. American journal of obstetrics and gynecology 172:14-18.

36. Quinn S, Chin W, Walbridge J (2015) MR-guided focused ultrasound for the treatment of adenomyosis: current insights. Research and Reports in Focused Ultrasound:1. http://https://doi.org/10. 2147/RRFU.S95901.

37. Zhang L, Rao F, Setzen R (2017) High intensity focused ultrasound for the treatment of adenomyosis: selection criteria, efficacy, safety and fertility. Acta Obstet Gynecol Scand 96:707714. http://https://doi.org/10.1111/aogs.13159.

38. Jeng C-J, Ou K-Y, Long C-Y et al (2020) 500 Cases of Highintensity Focused Ultrasound (HIFU) Ablated Uterine Fibroids and Adenomyosis. Taiwanese Journal of Obstetrics and Gynecology 59:865-871. http://https://doi.org/10.1016/j.tjog.2020.09.013.

39. Stewart EA, Rabinovici J, Tempany CM et al (2006) Clinical outcomes of focused ultrasound surgery for the treatment of uterine fibroids. Fertil Steril 85:22-29. http://https://doi.org/10.1016/j. fertnstert.2005.04.072.

40. Mindjuk I, Trumm CG, Herzog P et al (2015) MRI predictors of clinical success in MR-guided focused ultrasound (MRgFUS) treatments of uterine fibroids: results from a single centre. Eur Radiol 25:1317-1328. http://https://doi.org/10.1007/ s00330-014-3538-6.

41. Kim YS, Bae DS, Park MJ et al (2014) Techniques to expand patient selection for MRI-guided high-intensity focused ultrasound ablation of uterine fibroids. AJR Am J Roentgenol 202:443-451. http://https://doi.org/10.2214/ajr.13.10753.

42. Moroni RM, Martins WP, Messina MDL et al (2016) Highintensity focused ultrasound for symptomatic uterine fibroids. Cochrane Database of Systematic Reviews. http://https://doi.org/ 10.1002/14651858.CD012444.

43. Duc NM, Keserci B (2018) Review of influential clinical factors in reducing the risk of unsuccessful MRI-guided HIFU treatment outcome of uterine fibroids. Diagnostic and interventional radiology (Ankara, Turkey) 24:283-291. http://https://doi.org/10.5152/ dir.2018.18111.

Publisher's Note Springer Nature remains neutral with regard to jurisdictional claims in published maps and institutional affiliations. 